\title{
Left ventricular dysfunction in potential heart donors and its influence on recipient outcomes
}

\author{
Jonatan Oras, $\mathrm{MD}, \mathrm{PhD},{ }^{\mathrm{a}}$ Rana Doueh, $\mathrm{MD},{ }^{\mathrm{a}}$ Erik Norberg, $\mathrm{MD},{ }^{\mathrm{a}}$ Björn Redfors, $\mathrm{MD}, \mathrm{PhD},{ }^{\mathrm{b}}$ \\ Elmir Omerovic, $\mathrm{MD}, \mathrm{PhD},{ }^{\mathrm{b}}$ and Göran Dellgren, $\mathrm{MD}, \mathrm{PhD}^{\mathrm{c}}$
}

\section{ABSTRACT}

Objectives: New onset of left ventricular (LV) dysfunction in organ donors is frequent and considered as a contraindication for utilization of the heart. However, such dysfunction might be caused by sympathetic stress and could be transient (Takotsubo syndrome). In this study, we assessed the incidence, pattern, and predictors of LV dysfunction in potential heart donors and evaluated its influence on recipient outcomes.

Methods: Donor records of consecutive organ donors in western Sweden between 2006 and 2016 were reviewed. Recipients of transplanted donor hearts were identified in the Scandiatransplant database.

Results: Of 641 potential heart donors who underwent echocardiographic assessment, LV dysfunction (ejection fraction $<50 \%$ and/or regional hypokinesia) was found in 155 donors (24\%). Regional hypokinesia was seen in 113 donors of whom 46 had a Takotsubo-like circumferential hypokinetic pattern. Independent donor variables associated with LV dysfunction were a younger age, cardiac arrest as a contributing factor to death, need for inotropic support, and a shorter time from admission to declaration of brain death. A total of $338(54 \%)$ donor hearts were transplanted, of which 45 (14\%) had LV dysfunction. LV dysfunction was a major determinant of not transplanting the heart $(P<.001)$. After transplantation, LV function normalized in the recipients. Neither short-term outcomes nor the composite end point of death or retransplantation over time differed between recipients of donor hearts with versus without LV dysfunction $(P=.587)$.

Conclusions: LV dysfunction is common among potential heart donors. These hearts were safely transplanted in this study. The use of these hearts might significantly increase transplantation rates. (J Thorac Cardiovasc Surg 2020;159:1333-41)

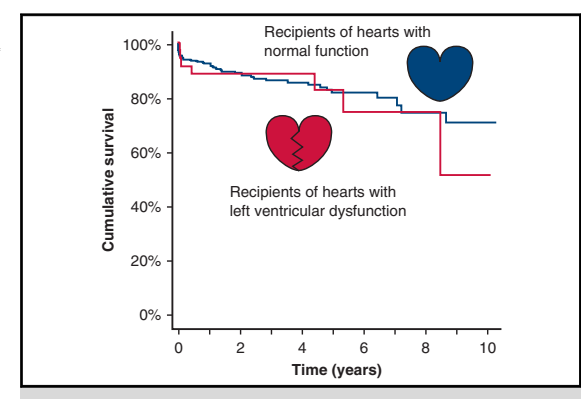

Outcomes of recipients of hearts with left ventricular dysfunction versus normal function.

\section{Central Message}

Donor hearts with left ventricular dysfunction were safely transplanted in this study. Systematic use of such hearts have the potential to significantly increase transplantation rates.

\section{Perspective}

Heart transplantation is strictly limited because of organ shortage. Left ventricular dysfunction is regarded as a contraindication for use of a donor heart. This study showed that cardiac dysfunction after brain death is common but often transient and such hearts can be safely transplanted. Systematic use of such hearts could make heart transplantation available to more patients.

See Commentaries on pages 1342 and 1343.

\footnotetext{
From the ${ }^{\mathrm{a}}$ Department of Anesthesiology and Intensive Care Medicine, Institute of Clinical Sciences, ${ }^{\mathrm{b}}$ Department of Cardiology, Institute of Medicine, and ${ }^{\mathrm{c}}$ Transplant Institute, University of Gothenburg, Sahlgrenska Academy, Gothenburg, Sweden.

This work was supported by the Swedish Heart-Lung Foundation (grant number 20170631), the Swedish state under the agreement between the Swedish government and the country councils, the ALF-agreement (ALFGBG- 775041), the Gothenburg Medical Society (GLS-691151), and the Memorial Foundation of Lars-Erik Gelin.

Received for publication Feb 6, 2019; revisions received June 3, 2019; accepted for publication June 18, 2019; available ahead of print Aug 16, 2019.

Address for reprints: Jonatan Oras, $\mathrm{MD}, \mathrm{PhD}$, Blå Stråket 5, våning 5, 41545 Gothenburg, Sweden (E-mail: jonatan.oras@vgregion.se).

0022-5223

Copyright (C) 2019 by The American Association for Thoracic Surgery. Published by Elsevier Inc. This is an open access article under the CC BY-NC-ND license (http:// creativecommons.org/licenses/by-nc-nd/4.0/).

https://doi.org/10.1016/j.jtcvs.2019.06.070
}

Refractory heart failure is a condition with a very poor prognosis. ${ }^{1}$ Despite advances in heart failure treatment with pharmacotherapy, resynchronization, and ventricular assist devices, heart transplantation is still considered the best alternative for end-stage heart failure patients. ${ }^{2}$ Unfortunately, there is a shortage of donor hearts, which limits the number of possible transplantations, and patients are

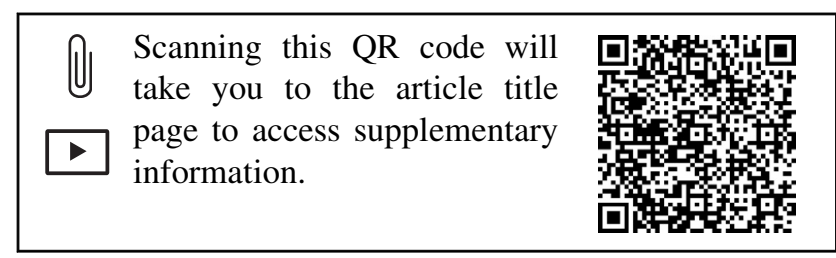




\section{Abbreviations and Acronyms \\ $\mathrm{CAD}=$ coronary artery disease \\ CI = confidence interval \\ Echo = echocardiogram \\ $\mathrm{EF}=$ ejection fraction \\ ICU = intensive care unit \\ $\mathrm{IQR} \quad=$ interquartile range \\ $\mathrm{LV} \quad=$ left ventricular \\ RWMA $=$ regional wall motion abnormalities}

dying while awaiting transplantation. ${ }^{3,4}$ It is therefore important that as many usable heart donors as possible are identified.

Many potential heart donors without preexisting cardiac disease or other contraindications for transplantation are disqualified because they develop unexpected heart failure. According to the current guidelines, donors with regional wall motion abnormalities (RWMA) and low ejection fractions (EFs) should not be used for transplantation. There is a consensus that such hearts should be transplanted with great caution, and such abnormalities are a major determinant of whether a heart should be used..$^{7-9}$ However, left ventricular (LV) dysfunction in the context of brain death could be temporary. ${ }^{10,11}$ When brain death occurs, there is a significant release of catecholamines. ${ }^{11-13}$ This catecholamine surge might trigger Takotsubo syndrome, which is an acute cardiac condition involving the rapid onset of reversible regional hypokinesia in the left ventricle. ${ }^{14-17}$ Because cardiac dysfunction is usually transient in these situations, these hearts have been successfully transplanted as previously described by us and others. ${ }^{18-20}$

Despite that LV dysfunction is frequently observed in potential heart donors and that some of these hearts have been successfully used clinically, the subject has not been sufficiently studied. Therefore, we sought to study the incidence, patterns, and predictors of LV dysfunction in potential heart donors and its influence on recipient outcomes.

\section{METHODS}

This study was approved by the regional ethics committee in Gothenburg, Sweden (approval date July 18, 2016; number 678-16). Our hospital is the center for cardiac, lung, liver, kidney, and pancreatic transplantation in western and northern Sweden, which is an area with a total population of approximately 3 million people. We have coordination programs with the other transplant departments in Sweden and the other northern countries (Denmark, Norway, Finland, and Iceland) through the Scandiatransplant organization. All donors in the study were donors after brain death because there was no program for donation after circulatory death in Sweden during the study period.

\section{Acquisition of Donor Data}

According to Swedish law, all organ donors need to have a record of the transplantation process. In this record, all data of importance for the donation process are registered. All records of potential organ donors from
October 2006 to October 2016 were reviewed. The donors included in the study were considered as eligible organ donors according to current definitions. All donors considered for heart donation who underwent an echocardiographic examination were included in this study. The following data were retrieved from the donor records: age, sex, medical history, body mass index, cause of death, factors contributing to death, time from admission to brain death, echocardiographic, and angiographic data. If an echocardiogram (echo) or angiographic record was missing, the donor's hospital was contacted to acquire the missing data. LV dysfunction was defined as global hypokinesia with an $\mathrm{EF}<50 \%$ and/or the presence of RWMA. Risk factors for coronary artery disease (CAD) was defined as having either of diabetes, hypertension, hyperlipidemia, or active smoker.

The echocardiographic data used in the study was on the basis of echo reports from each donor center. These examinations are performed by certified echo lab physicians or cardiologist, according to a standard protocol. In this protocol, there is an individual evaluation of $16 \mathrm{LV}$ segments. The LV $\mathrm{EF}$ is routinely estimated by eye-balling. Angiography was performed in patients who were considered to be at risk of having $\mathrm{CAD}$, according to current recommendations (Appendix E1). ${ }^{21}$

\section{Donor Management}

The donors were treated according to a national protocol that was in accordance with the recommendations of the European Committee on Organ Transplantation. According to Swedish law, the donation process should be finalized and donation operation initiated within 24 hours of declaration of death. Echocardiography is typically repeated, whenever possible, every 6th to 12 hours in donors with LV dysfunction. Donor management is provided in the Appendix E1.

\section{Recipient Data}

Transplant recipients were identified using the Scandiatransplant database. Data regarding postoperative interventions were acquired from a local database. The recipient data related to echocardiography and angiography were acquired from the patient records. The time to death was acquired from the Swedish population registry, and the time to eventual retransplantation was collected from the Scandiatransplant registry.

\section{Statistics}

Normally distributed variables are presented as the mean \pm standard deviation, and the non-normally distributed variables are presented as the median (interquartile range [IQR]). $T$ tests were used to compare the means of the normally distributed variables, and Mann-Whitney $U$ tests were used to compare the distributions of the non-normally distributed variables. For estimation of median differences between groups, the Hodges-Lehman estimator was used. Fisher exact tests were used to compare the binary variables. A linear mixed model and binary logistic mixed model, with an autoregressive covariance matrix, was used for evaluation of $\mathrm{EF}$ and proportion of patients exhibiting resolution of RWMA over time, respectively. Logistic regression was used to identify the variables that were associated with LV dysfunction and the acceptance of a heart for donation and to compare the 30-day mortalities between the recipients of hearts with and without LV dysfunction. Kaplan-Meier curves with log rank tests and Cox regressions, for calculation of hazard ratios and in the adjusted analysis, were used to compare the survival and retransplant rates over time between the different groups. In the multivariable analysis, all variables with a $P$ value $<.10$ in univariate analysis were included in the multivariable analysis. IBM SPSS Statistics, Version 24.0 (IBM Corp, Armonk, NY) was used in the analyses.

\section{RESULTS \\ Study Population}

The records of 975 eligible organ donors were reviewed, and 306 were considered unacceptable for heart donation 
because of a history of cardiac disease $(n=157)$, age older than 65 years $(n=64)$, a lack of a suitable recipient $(\mathrm{n}=31)$, or other reasons $(\mathrm{n}=25)$. The remaining 669 donors were considered as potential heart donors and underwent echocardiographic examination. Echocardiographic records were available for $641(96 \%)$ of these donor candidates (Figure 1).

\section{Baseline Donor Characteristics}

In the donor cohort, $53 \%(\mathrm{n}=341)$ were women, and the median age was 50 (IQR, 35-59; range, 0-72) years. A total of 366 patients $(58 \%)$ ) had at least 1 risk factor for CAD; 55 $(9 \%)$ had a history of vascular disease, and $17(3 \%)$ had a history of LV hypertrophy or mild valvular heart disease. The median time to death occurred on day 2 (24-48 hours) after admission (IQR, days 2-4). The most common cause of brain death was a cerebral insult $(59 \% ; \mathrm{n}=378)$, followed by hypoxic brain edema $(21 \% ; \mathrm{n}=136)$, and traumatic brain injury $(17 \% ; n=108)$. The occurrence of cardiac arrest between symptom onset and the declaration of brain death was observed in $31 \%(n=199)$ of the donors (Table 1).

\section{Dysfunction in Potential Heart Donors}

Of the 641 donors included in the study, 155 donors (24\%) had LV dysfunction. RWMA were observed in 113 donors $(18 \%)$ and were more frequent than global LV dysfunction, which was observed in 32 donors $(5 \%)$. In 10 donors $(1.5 \%)$, the presence versus absence of RWMA was uncertain or not able to assess. Of the donors with RWMA, 37 had a preserved global LV function with an
$\mathrm{EF}>50 \%$. The mean EFs for each cohort were $60 \pm 4 \%$ for the donors with normal function and $42 \pm 11 \%$ for the donors with LV dysfunction (Figure 2).

A circumferential pattern of RWMA, resembling the typical Takotsubo phenotype, was observed in $46(41 \%)$ of the donors with RMWA. Of these donors, the apical, midventricular and basal Takotsubo variants were observed in $43 \%, 14 \%$, and $43 \%$ of donors, respectively. Among the donors with a noncircumferential pattern, the septal segments were the most commonly affected (Figure 2). There were no differences in baseline characteristics between donors having the circumferential versus noncircumferential phenotype. Detailed data regarding the distribution of RWMA for each donor is available in Figure E1.

In 29 donors with LV dysfunction, echocardiography was repeated during the 24-hour donation process. Nineteen donors $(66 \%)$ exhibited improvements in the LV function, and 14 achieved normalization of LV function (Figure E2). Ten of these donors were finally transplanted $(71 \%)$. Cardiac arrest as a contributing factor to death was the only of the donor baseline variables that was associated with normalization of LV function (odds ratio, 7.2 [95\% confidence interval (CI), 1.35-38.3]; $P=.021)$.

\section{Donor Variables Associated With LV Dysfunction in Potential Heart Donors}

The donors with LV dysfunction were younger and more often had a history of psychiatric disease. They were more likely to have suffered from cerebral edema as the cause of death and to have suicide, intoxication, or cardiac arrest as a

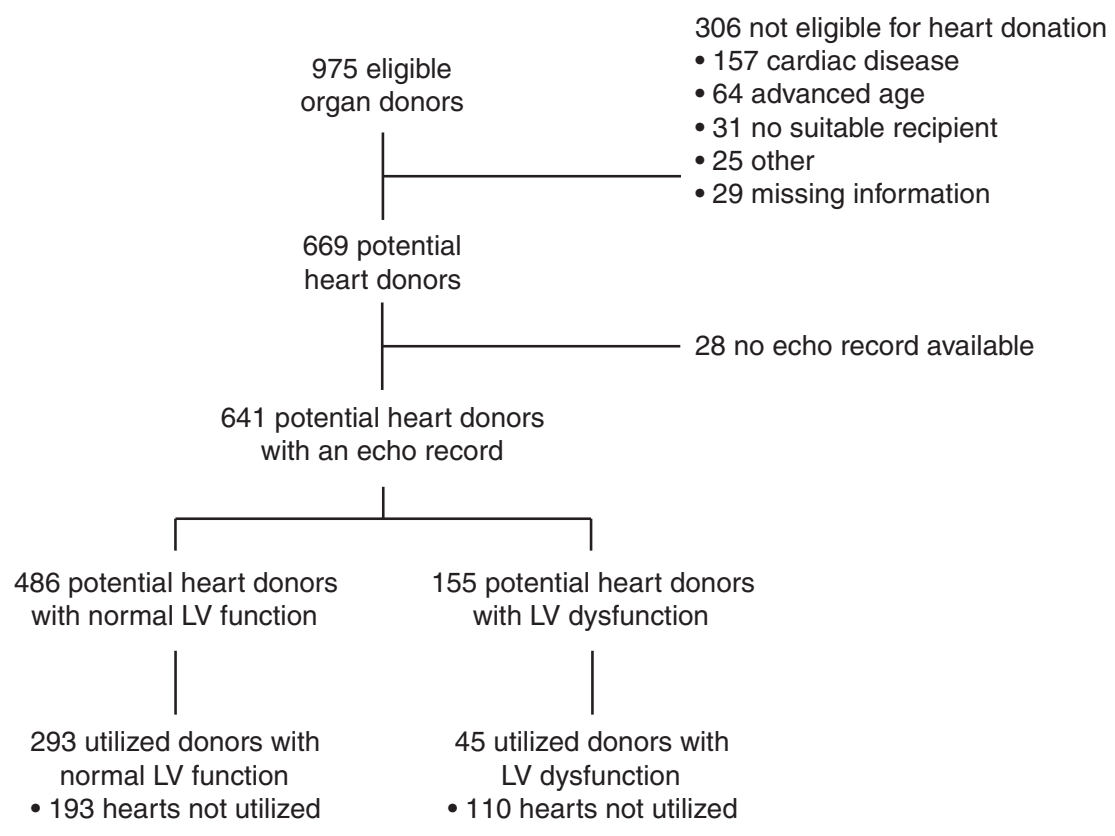

FIGURE 1. Study flow chart. Echo, Echocardiography; $L V$, left ventricle. 
TABLE 1. Baseline characteristics

\begin{tabular}{|c|c|c|c|c|}
\hline Category & Variable & Normal $(n=486)$ & Left ventricular dysfunction $(n=155)$ & $P$ value \\
\hline \multirow[t]{4}{*}{ Background data } & Female sex & $250(52)$ & $91(59)$ & .177 \\
\hline & Age (range), y & $52(38-60)$ & $47(27-56)$ & .004 \\
\hline & Body mass index & $25 \pm 5$ & $25 \pm 5$ & .334 \\
\hline & Admission to brain death (range), $d$ & $2(2-4)$ & $2(2-3)$ & .019 \\
\hline \multirow[t]{14}{*}{ Medical history } & Smoker & $214(44)$ & $68(44)$ & $>.999$ \\
\hline & Hypertension & $123(25)$ & $31(20)$ & .196 \\
\hline & Diabetes & $20(4)$ & $5(3)$ & .646 \\
\hline & Hyperlipidemia & $12(2)$ & $4(3)$ & $>.999$ \\
\hline & Ethanol overconsumption & $65(13)$ & $14(9)$ & .163 \\
\hline & Drug abuse & $28(6)$ & $12(8)$ & .445 \\
\hline & Cardiac disease & $13(3)$ & $4(3)$ & $>.999$ \\
\hline & Vascular disease & $42(9)$ & $13(8)$ & $>.999$ \\
\hline & Renal disease & $7(1)$ & $3(2)$ & .711 \\
\hline & Pulmonary disease & $29(6)$ & $9(6)$ & $>.999$ \\
\hline & Psychiatric disease & $54(11)$ & $32(21)$ & .004 \\
\hline & Neurological disease & $20(4)$ & $9(6)$ & .378 \\
\hline & Liver disease & $10(2)$ & $1(1)$ & .475 \\
\hline & Other & $38(8)$ & $11(7)$ & .863 \\
\hline \multirow[t]{10}{*}{ Cause of death } & Hypoxic brain edema & $85(17)$ & $51(33)$ & $<.001$ \\
\hline & Circulatory arrest & $39(8)$ & $27(17)$ & $<.001$ \\
\hline & Respiratory failure/hypoxia & $32(7)$ & $16(10)$ & .159 \\
\hline & Other & $14(3)$ & $8(5)$ & .204 \\
\hline & Cerebral insult & $296(61)$ & $82(53)$ & .091 \\
\hline & Intracerebral hemorrhage & $117(24)$ & $20(13)$ & .003 \\
\hline & Subarachnoid hemorrhage & $137(28)$ & $51(33)$ & .267 \\
\hline & Other insult & $42(8)$ & $11(7)$ & .736 \\
\hline & Traumatic brain injury & $89(18)$ & $19(12)$ & .085 \\
\hline & Other & $16(3)$ & $3(2)$ & .587 \\
\hline \multirow[t]{3}{*}{ Contributing factors } & Suicide & $23(5)$ & $15(10)$ & .031 \\
\hline & Intoxication & $11(2)$ & $9(6)$ & .035 \\
\hline & Cardiac arrest & $123(25)$ & $76(49)$ & $<.001$ \\
\hline \multirow[t]{2}{*}{ Treatment } & Inotropic support & 139 (29) & $66(43)$ & .001 \\
\hline & Use of norepinephrine & $359(74)$ & $112(72)$ & .678 \\
\hline
\end{tabular}

Data are presented as n (\%) except where otherwise noted. Cardiac disease refers to known cardiac hypertrophy or mild valvular disease. Inotropic support refers to use of dobutamine or dopamine.

factor contributing to death. Furthermore, these donors had a shorter time to the declaration of brain death and more commonly had inotropic support (dopamine or dobutamine; Table 1). In a multivariable regression model, age, cardiac arrest as a factor contributing to death, time to brain death, and the use of inotropic support were found to be independently associated with LV dysfunction (Table 2).

\section{Coronary Angiography}

Coronary angiography was performed in 214 donors, and 28 of these donors had RWMA. CAD was revealed in 3 of the 28 donors with RWMA. In 1 of these 3 donors, there was a discrepancy between the hypokinetic segments in the left ventricle and coronary artery stenosis. Angiographic evidence of CAD was not more common in the donors with normal function $(\mathrm{n}=31 ; 16 \%)$ versus those with RWMA $(\mathrm{n}=3 ; 11 \% ; P>.999)$.

\section{Dysfunction and Heart Transplantation}

The hearts of 338 of the 641 potential heart donors included in the study were transplanted, including those from 293 of the $486(60 \%)$ donor candidates with normal 


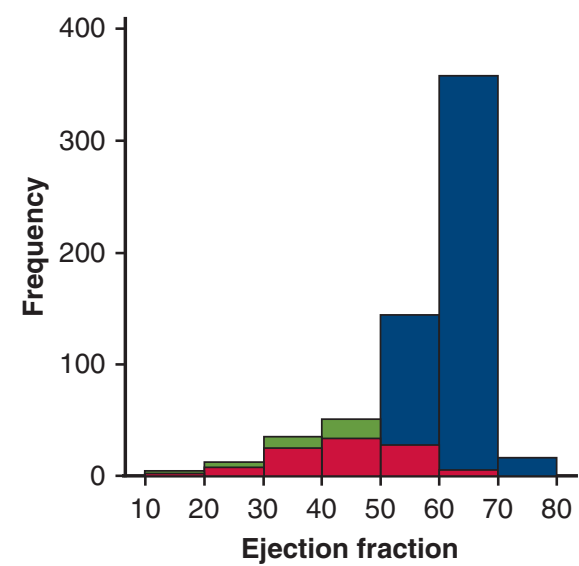

A $\square$ Global LV dysfunction

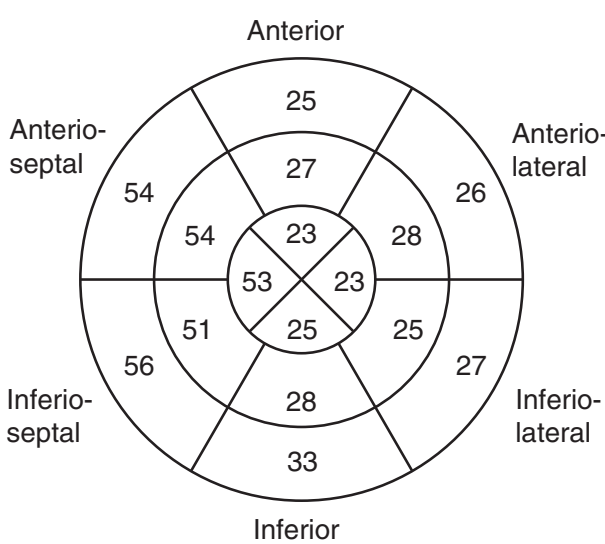

B

FIGURE 2. A, Ejection fraction in potential heart donors. The bars represent number of potential heart donors with respective ejection fraction. The data are separated for the donors with normal left ventricular ( $L V$ ) function (blue), global LV dysfunction ( $g r e e n)$, and with regional wall motion abnormalities (red). B, Proportion of segments affected in the donors with regional wall motion abnormalities. Numbers represent percentage of donors with regional wall motion abnormalities, having the segment affected. The outer circle represents basal segments, the middle circle represents midventricular segments, and the inner circle represents apical segments. Septal segments were more commonly affected. Detailed descriptions of the distributions of regional wall motion abnormalities in each donor are presented in Figure E1. RWMA, Regional wall motion abnormalities.

function and 45 of the $155(29 \%)$ donor candidates with LV dysfunction. LV dysfunction was an independent predictor of not transplanting the heart after multivariable adjustment for age, history of cardiac disease, risk factors for cardiac disease, and body mass index (odds ratio, 4.74 [95\% CI, 3.11-7.25]; $P<.001$ ). There were no differences in baseline characteristics between the transplanted donors with LV dysfunction and those with normal LV function (Table E1).

TABLE 2. Multivariable analysis of the variables associated with left ventricular dysfunction in eligible heart donors

\begin{tabular}{llc}
\hline \multicolumn{1}{c}{ Variable } & OR $(\mathbf{9 5} \% \mathbf{C I})$ & $\boldsymbol{P}$ value \\
\hline $\begin{array}{l}\text { Cardiac arrest as a factor } \\
\text { contributing to death }\end{array}$ & $2.28(1.38-3.78)$ & .001 \\
\hline $\begin{array}{l}\text { Use of inotropic support* } \\
\text { Admission to declaration of } \\
\text { brain death, per day }\end{array}$ & $1.81(1.20-2.73)$ & .004 \\
\hline $\begin{array}{l}\text { Age, per 10 years } \\
\text { Psychiatric disease in medical } \\
\text { history }\end{array}$ & $0.91(0.84-0.98)$ & .019 \\
\hline $\begin{array}{l}\text { Cerebral hemorrhage as cause } \\
\text { of death }\end{array}$ & $1.53(0.84-2.80)$ & .020 \\
\hline $\begin{array}{l}\text { Hypoxic brain edema as cause } \\
\text { of death }\end{array}$ & $1.26(0.70-2.78-2.57)$ & .254 \\
\hline $\begin{array}{l}\text { Intoxication as a factor } \\
\text { contributing to death }\end{array}$ & $1.37(0.47-3.97)$ & .545 \\
\hline $\begin{array}{l}\text { Suicide as a factor } \\
\text { contributing to death }\end{array}$ & $0.81(0.34-1.94)$ & .639 \\
\hline
\end{tabular}

All baseline variables with a $P$ value $<.10$ in univariate regression were included in this multivariable analysis. $O R$, Odds ratio; $C I$, confidence interval. *Inotropic support refers to dopamine or dobutamine.
Of the 45 donors with LV dysfunction whose hearts were transplanted, $38(84 \%)$ had RWMA with a mean EF of $50 \% \pm 7 \%$ and a median number of hypokinetic segments of 5 (IQR, 4-8). Among the 7 donors who had global LV dysfunction, the mean $\mathrm{EF}$ was $42 \% \pm 5 \%$. Of the transplanted hearts with LV dysfunction, 16 had an EF of $40 \%$ to $50 \%, 5$ had an $\mathrm{EF}<40 \%$, and 21 donors had RWMA with an $\mathrm{EF}>50 \%$. A total of 276 donor hearts were transplanted at the transplant center in Gothenburg and had detailed available follow-up data. Of these donors, 38 had LV dysfunction.

\section{Recipient Characteristics}

The subgroup of 276 recipients of a transplanted heart at the center in Gothenburg had a median age of 50 (IQR, 2961 ; range, $0-71$ ) years, and $71 \%$ were male. The mean pretransplant EF was $25 \% \pm 11 \%$, and $80(29 \%)$ were bridged with mechanical circulatory support. The median ischemic time at transplantation was 200 (IQR, 159-231) minutes. There were no differences in pre- or perioperative characteristics between the recipients of hearts with LV dysfunction and receipts of hearts with normal LV function (Table E2).

\section{Resolution of LV Dysfunction and Coronary Angiography in the Recipients}

All recipients of donor hearts with LV dysfunction exhibited improved function post-transplantation. Specifically, the EF improved from $47 \% \pm 8 \%$ in the transplanted donors with LV dysfunction to $55 \% \pm 10 \%$ at the first postoperative echocardiography $(P<.001)$. 


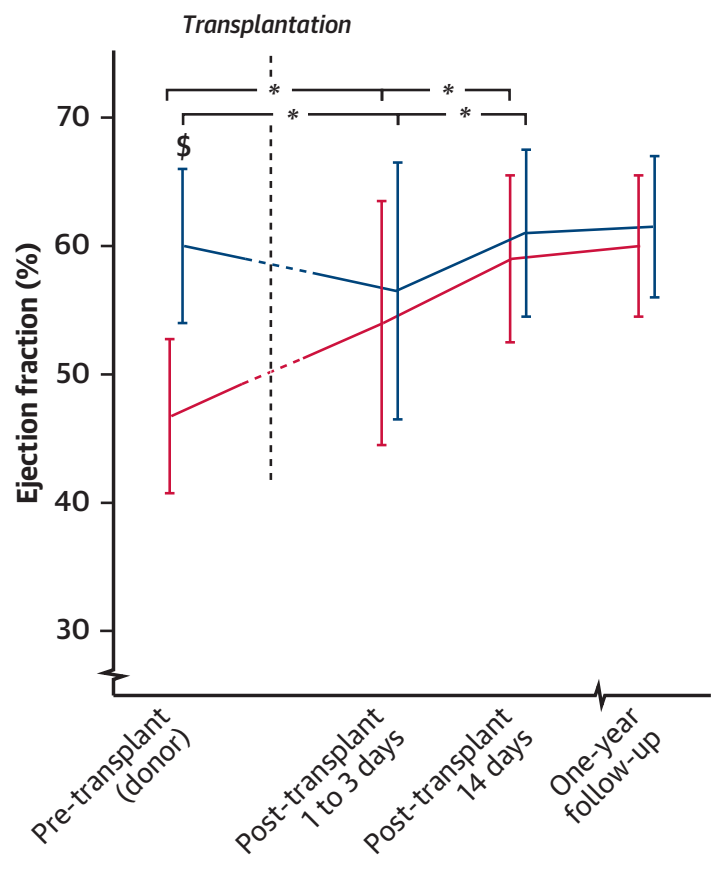

Recipients of donor hearts with:

Normal function

A

\section{Left ventricular dysfunction}

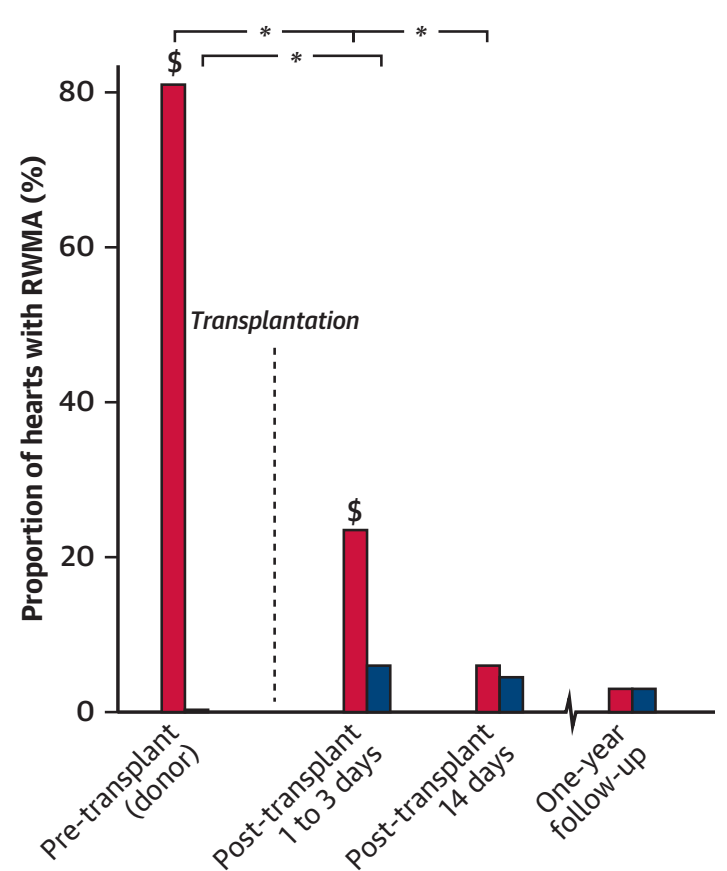

Recipients of donor hearts with:

Normal function

Left ventricular dysfunction

FIGURE 3. A, Temporal changes in the ejection fractions. Changes in ejection fraction over time from pretransplant (far left) to one-year follow up ( far right). The blue line represents recipients of hearts with normal function, the red line represents recipients of hearts with left ventricular dysfunction. There were no differences in ejection fraction at any time-point post-transplantation. The bars represent the $95 \%$ confidence intervals for the ejection fractions. B, Temporal changes in normalization of regional wall motion abnormalities. The bars represent proportions of hearts having regional wall motion abnormalities from pretransplantation (far left) to one-year follow up (far right). Blue bars represent recipients of hearts with normal function, the red bars represent recipients of hearts with left ventricular dysfunction. Regional hypokinesia resolved post-transplantation and there were no differences between the groups two weeks postoperatively. $* P<.05$ within group, $\$ P<.05$ between groups. The dashed black line represents time of transplantation. $R W M A$, Regional wall motion abnormalities.

The EF did not differ between the recipients of the hearts with normal function and the recipients of hearts with LV dysfunction at 2 weeks post-transplantation $(61 \% \pm 6 \%$ vs $59 \% \pm 6 \% ; P=.481)$ or at the 1 -year follow-up $(62 \% \pm 5 \%$ vs $60 \% \pm 5 \% ; P=.157$; Figure 3$)$. In the transplanted donor hearts with RWMA, hypokinesia successively resolved in the recipients. At the first postoperative echocardiography, RWMA was completely resolved in $25(76 \%)$ recipients. At the 1-year follow-up, 1 patient $(3 \%)$ had RWMA. This patient had a perioperative coronary artery complication resulting in myocardial ischemia. This was diagnosed directly postoperatively with coronary angiography and distribution of RWMA postoperatively was not similar to the donor echo. Immediately postoperatively, hypokinesia was more common in the recipients of donor hearts with LV dysfunction than in the recipients of donor hearts with normal function $(24 \%$ vs $6 \% ; P=.003)$, but this was not the case at 2 weeks postoperatively $(6 \%$ vs $5 \%$; $P=.693)$ or at the 1-year follow-up (3\% vs $3 \%$;
$P>$.999; Figure 3). Coronary angiographies at the 1-year follow-up did not show CAD in any of the recipients of hearts from donors with LV dysfunction.

\section{Influence of LV Dysfunction on Recipient Outcomes}

The use of postoperative mechanical circulatory support or intra-aortic balloon pump was higher, but was not statistically significant, in recipients of hearts with LV dysfunction versus normal function ( $24 \%$ vs $12 \%$; mean difference, $11.3 \%$ [95\% CI, -2.8 to 25.5$] ; P=.073$ ). There were no differences in intensive care unit (ICU) interventions, including time with inotropic support, time on ventilator, renal replacement therapy, or ICU days, between the groups. There were also no differences in the risk of acute rejection, sepsis, or reoperations between the recipients of hearts with normal function and the recipients of hearts with dysfunction (Table 3).

The mortality and retransplantation rates were available for all recipients in Sweden (the transplant centers in Gothenburg and Lund). There were a total of 298 recipients, 
TABLE 3. Use of postoperative advanced hemodynamic support, rejection, and ICU interventions in the recipients of hearts with normal function and LV dysfunction

\begin{tabular}{|c|c|c|c|c|c|}
\hline \multirow[b]{2}{*}{ Category } & \multicolumn{2}{|c|}{ Donor heart } & \multirow[b]{2}{*}{$\begin{array}{c}\text { Mean } / \text { median } \\
\text { difference }(95 \% \mathrm{CI})\end{array}$} & \multirow[b]{2}{*}{$\begin{array}{c}\text { Relative risk } \\
(95 \% \text { CI })\end{array}$} & \multirow[b]{2}{*}{$P$ value } \\
\hline & $\begin{array}{l}\text { Normal function } \\
\quad(n=238)\end{array}$ & $\begin{array}{l}\text { LV dysfunction } \\
(\mathrm{n}=38)\end{array}$ & & & \\
\hline Postoperative VAD/ECMO, n (\%) & $24(10)$ & $6(16)$ & $6.6 \%(-17.8$ to 6.6$)$ & $1.52(0.69-3.3)$ & .398 \\
\hline Postoperative IABP, n (\%) & $14(6)$ & $4(11)$ & $4.6 \%(-14.8$ to 5.6$)$ & $1.67(0.66-4.2)$ & .291 \\
\hline Postoperative CRRT, n (\%) & $54(23)$ & $9(24)$ & $0.6 \%(-15.1$ to 13.9$)$ & $1.03(0.52-2.1)$ & $>.999$ \\
\hline Time with inotropes, $\mathrm{d}$ & $6 \pm 10 / 3(2-6,0-77)$ & $8 \pm 11 / 3(2-9,0-38)$ & $0.4(-0.5$ to 1.4$)$ & & .435 \\
\hline Mechanical ventilation, $\mathrm{d}$ & $3 \pm 9 / 1(0-2,0-73)$ & $5 \pm 9 / 1(0-6,0-37)$ & $2(-2$ to 27$)$ & & .296 \\
\hline Sepsis, n (\%) & $26(11)$ & $7(18)$ & $7.3 \%(-20.2$ to 5.7$)$ & $1.63(0.78-3.4)$ & .191 \\
\hline Rejection, n (\%) & $50(22)$ & $7(20)$ & $-1.7 \%(-16.0$ to 12.5$)$ & $0.92(0.42-2.0)$ & $>.999$ \\
\hline ICU days & $9 \pm 12 / 5(2-9,0-94)$ & $10 \pm 12 / 5(3-13,0-40)$ & $0(-1$ to 2$)$ & & .442 \\
\hline
\end{tabular}

The continuous variables were non-normally distributed and presented as mean \pm standard deviation/median (IQR, range). $L V$, Left ventricle; $C I$, confidence interval; $V A D$, ventricular assist device; $E C M O$, extracorporeal membrane oxygenation; IABP, intra-aortic balloon pump; $C R R T$, continuous renal replacement therapy; ICU, intensive care unit.

42 of whom received hearts with LV dysfunction. The short-term mortality (30 days) did not differ between the recipients of hearts with normal $\mathrm{LV}$ function $(\mathrm{n}=12$; $5 \%)$ and the recipients of hearts with LV dysfunction (n $=2 ; 5 \% ; P>.999)$. The long-term outcome of the combined end point of mortality or retransplantation over the study period did not differ between the recipients of hearts with normal LV function and the recipients of hearts with LV dysfunction (hazard ratio, 1.25 [95\% CI, 0.56-2.8]; $P=.588$; Figure 4 ). This finding did not change when adjusted for variables associated with an increased risk of death or retransplantation, namely recipient age, recipient pretransplantation ventricular assist device, extracorporeal circulation time, and ischemic time (hazard ratio, 1.03 [95\% CI, 0.39-2.72]; $P=.955)$. There was no increased risk of long-term events in recipients of hearts with an
$\mathrm{EF}<40 \%$, EF $40 \%$ to $50 \%$, or RWMA with $\mathrm{EF}>50 \%$ $(P=.698$; Figure E3). There were neither any differences in recipients of hearts with global dysfunction nor RWMA $(P=.090$; Figure E4).

\section{DISCUSSION}

The main findings of this study were as follows: (1) LV dysfunction affected almost 1 in 4 eligible heart donor candidates and was a major determinant of whether the heart was transplanted or not; (2) the hearts with LV dysfunction that were transplanted recovered their function in the recipient after the transplantation; and (3) the recipients of hearts with LV dysfunction did not have higher rates of postoperative complications and had short- and longterm survival similar to those of the recipients of hearts with normal LV function (Video 1).

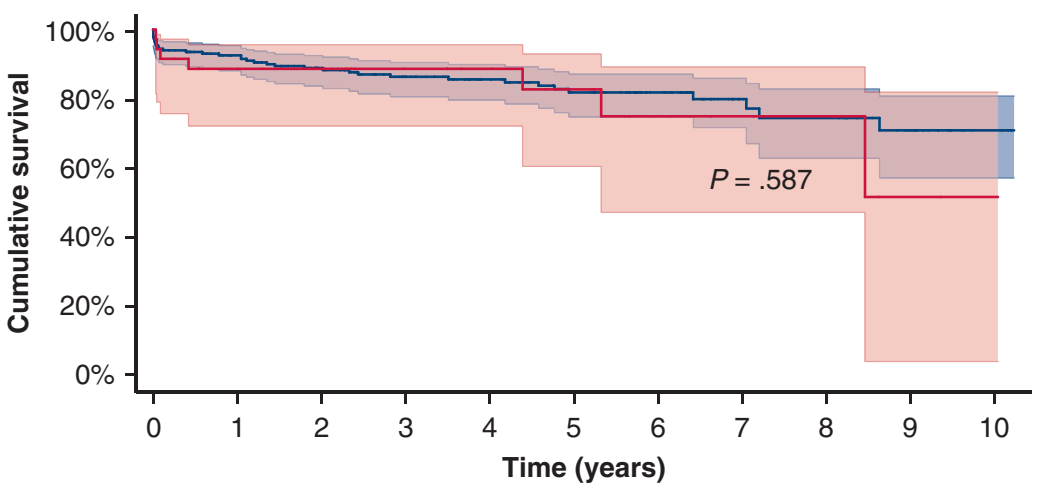

$\begin{array}{ccccccccccc}\begin{array}{c}\text { Numbers at risk } \\ \text { Normal 256 }\end{array} & 217 & 181 & 149 & 122 & 101 & 71 & 37 & 34 & 22 & 5 \\ \text { LV dysfunction } 42 & 35 & 30 & 22 & 19 & 15 & 9 & 6 & 5 & 2 & 1\end{array}$

Recipients of donor hearts with:

- Normal function _ Left ventricular dysfunction

FIGURE 4. Long-term outcomes of the recipients of hearts with normal function (blue line) and left ventricular dysfunction (red line). The events represented include death and re-transplantation. There were no differences in events over time between the groups. Shaded areas represent $95 \%$ confidence interval. $L V$, Left ventricular. 


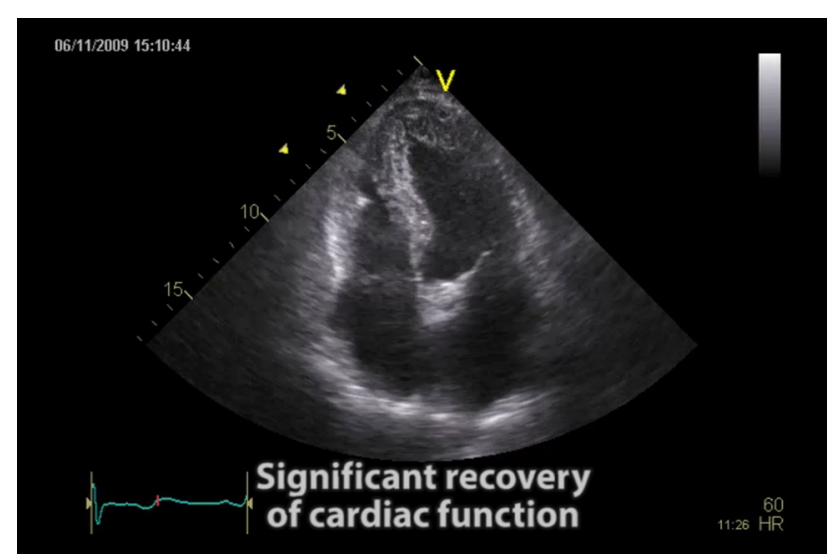

VIDEO 1. Video abstract summarizing the main findings in the report. Video available at: https://www.jtcvs.org/article/S0022-5223(19)31369-8/ fulltext.

In recent years, knowledge of Takotsubo syndrome, which is an acute cardiac syndrome characterized by the sudden onset of potentially reversible regional hypokinesia of the left ventricle, has increased. Takotsubo syndrome occurs in response to severe stress and is associated with sympathetic overactivity and excess catecholamines. ${ }^{14,15,17}$ Organ donors often suffer from extreme somatic stress. Conditions that cause brain death are hyperadrenergic per se and in brain herniation a catecholamine storm is typically observed. ${ }^{12,13,22}$ Because of the hyperadrenergic state in organ donors, it is plausible that many of them suffer from Takotsubo syndrome. Other reversible cardiac conditions associated with brain death include postcardiac arrest syndrome. ${ }^{23}$ In the present study, we found that almost 1 in 4 potential organ donors had LV dysfunction. This number is in accordance with recent data, suggesting that $20 \%$ of potential heart donors are not used because of LV dysfunction. ${ }^{6,24}$ Most potential donors had RWMA, and almost half of them presented with the typical Takotsubo pattern of hypokinesia. In total, 40 hearts with regional hypokinesia not typical for the Takotsubo syndrome underwent coronary angiography, either pre- or post-transplantation, that lacked angiographic evidence of CAD. Neurocardiogenic regional hypokinesia does not have to follow the Takotsubo pattern, ${ }^{25}$ so RWMA observed in potential heart donors, despite distribution of hypokinesia, should not be attributed to myocardial ischemia. In contrast, data from the present study suggest that nonischemic hypokinesia should be the first diagnosis to suspect but coronary angiography should be performed to rule out $\mathrm{CAD}$, at least in donors with risk factors. ${ }^{21}$

The most important predictors of LV dysfunction in the potential heart donors were a younger age, a short time from admission to the declaration of brain death, and cardiac arrest as a factor contributing to death. Cardiac arrest and postcardiac arrest syndrome are important reversible cardiac conditions associated with brain death. Postcardiac arrest syndrome is mostly associated with global LV dysfunction, but Takotsubo syndrome has been described and is not unusual in this condition. ${ }^{23,26} \mathrm{~A}$ short time of hospitalization before the declaration of brain death might be a marker of a more aggressive disease course with a rapid onset of brain herniation, which is associated with particularly high sympathetic activity. ${ }^{11}$ Young individuals have nonatrophied brains that leave less space for expansion in the intracranial cavity and usually exhibit a more aggressive disease course in intracranial emergencies.

Among the donors for whom echocardiography was repeated during the 24-hour donation process, LV function improved in most, and many of the donor hearts fully recovered LV function. Furthermore, all of the donor hearts with LV dysfunction that were transplanted recovered their global function in the recipient, and regressions of regional hypokinesia were observed. The need for advanced hemodynamic support was slightly more frequent among the recipients of hearts with LV dysfunction, but this difference was not statistically significant. Moreover, this difference did not have any influence on the length of ICU stay, other ICU measurements, or short-term outcomes. Furthermore, there were no differences in the mortality or retransplant rates between the recipients of hearts with normal $\mathrm{LV}$ function and the recipients of hearts with LV dysfunction over the long-term follow-up.

The major strengths of this study are the detailed donor and recipient data and the long-term follow-up data. Although the study was retrospective, the data were consecutively registered and the rates of missing echos was low $(4 \%)$. The main limitation of the present study was the limited number of patients who received transplanted hearts with LV dysfunction. There is a risk of statistical error because actual differences in recipients of hearts with LV dysfunction might not be detectable in such a small cohort. Nevertheless, the rate of transplants from donors with LV dysfunction was much higher than the rates that have been reported in previous studies on this subject. ${ }^{6,20,27}$ We found no differences in baseline variables between utilized donor hearts with $\mathrm{LV}$ dysfunction versus normal LV function. However, there could have been unmeasured variables in the donor heart selection process, in that the attending surgeons made clinical judgements about whether the use of particular hearts would be acceptable. Furthermore, echo reports from the donor hospitals were used in the echo interpretation. Unfortunately, the echo sequences were not obtainable from the donor hospitals from the first years of the study.

Our results have clinical implications because they directly challenge the current guidelines that recommend that donor hearts with RWMA should not be used. ${ }^{7}$ The scientific evidence for these recommendations is scarce and is, to a large extent, on the basis of data that are nearly 30 years old. ${ }^{28}$ Since that time, there have been considerable improvements in surgical techniques, intensive care, and advanced hemodynamic rescue therapies that have improved early outcomes after heart 
transplantation. ${ }^{29}$ The present study suggests that donor hearts with RWMA and slightly decreased EFs (EF $\geq 40 \%$ ) can be safely transplanted. Such donors constituted most (approximately $65 \%$ ) of the donor candidates with LV dysfunction and represented approximately $15 \%$ of the total donor pool. In donors with more pronounced LV dysfunction, watchful waiting is probably a good strategy to ensure that the heart function improves, with the caveat that this is accepted by local regulations. ${ }^{18,20}$ Our findings are directly supported by recent data suggesting that neither low EFs per se or RWMA in the donors affect recipient outcomes. ${ }^{6,20,27}$ Considering the data from this study and other novel data, we believe that it is time to consider changing the current guidelines.

\section{CONCLUSIONS}

LV dysfunction is common among potential heart donors and often leads to a decision to not transplant the heart. Our findings suggest that most donors with LV dysfunction suffer from transient regional hypokinesia and their hearts can be safely transplanted. Systematic utilization of these hearts might significantly increase transplantation rates.

\section{Conflict of Interest Statement}

Dr Oras received grants from the Swedish Heart-Lung Foundation, the Swedish state under the agreement between the Swedish government and the country councils (the ALF-agreement), the Gothenburg Medical Society, and the Memorial Foundation of Lars-Erik Gelin, during the conduct of the study. Dr Dellgren has received grants from Astellas A/S and Abbot, outside of the current study. All other authors have nothing to disclose with regard to commercial support.

\section{References}

1. Shah KS, Xu H, Matsouaka RA, Bhatt DL, Heidenreich PA, Hernandez AF, et al. Heart failure with preserved, borderline, and reduced ejection fraction: 5-year outcomes. J Am Coll Cardiol. 2017;70:2476-86.

2. Ponikowski P, Voors AA, Anker SD, Bueno H, Cleland JGF, Coats AJS, et al. 2016 ESC guidelines for the diagnosis and treatment of acute and chronic heart failure: the Task Force for the diagnosis and treatment of acute and chronic heart failure of the European Society of Cardiology (ESC) developed with the special contribution of the Heart Failure Association (HFA) of the ESC. Eur Heart J. 2016;37:2129-200.

3. Branger P, Samuel U. Eurotransplant International Foundation Annual Report 2016. Den Haag: CIP-Gegevens Koniklijke bibliotheek; 2017.

4. Mehra MR, Canter CE, Hannan MM, Semigran MJ, Uber PA, Baran DA, et al. The 2016 International Society for Heart Lung Transplantation listing criteria for heart transplantation: a 10-year update. J Heart Lung Transplant. 2016;35:1-23.

5. Dujardin KS, McCully RB, Wijdicks EF, Tazelaar HD, Seward JB, McGregor CG, et al. Myocardial dysfunction associated with brain death: clinical, echocardiographic, and pathologic features. J Heart Lung Transplant. 2001:20:350-7.

6. Khush KK, Menza R, Nguyen J, Zaroff JG, Goldstein BA. Donor predictors of allograft use and recipient outcomes after heart transplantation. Circ Heart Fail. 2013;6:300-9.

7. Kobashigawa J, Khush K, Colvin M, Acker M, Van Bakel A, Eisen H, et al. Report from the American Society of Transplantation Conference on Donor Heart Selection in Adult Cardiac Transplantation in the United States. Am J Transplant. 2017;17: 2559-66.
8. Costanzo MR, Dipchand A, Starling R, Anderson A, Chan M, Desai S, et al. The International Society of Heart and Lung Transplantation guidelines for the care of heart transplant recipients. J Heart Lung Transplant. 2010;29:914-56.

9. Zaroff JG, Babcock WD, Shiboski SC. The impact of left ventricular dysfunction on cardiac donor transplant rates. J Heart Lung Transplant. 2003;22:334-7.

10. Guglin M. How to increase the utilization of donor hearts? Heart Fail Rev. 2015; 20:95-105.

11. Shivalkar B, Van Loon J, Wieland W, Tjandra-Maga TB, Borgers M, Plets C, et al. Variable effects of explosive or gradual increase of intracranial pressure on myocardial structure and function. Circulation. 1993;87:230-9.

12. Chiari P, Hadour G, Michel P, Piriou V, Rodriguez C, Budat C, et al. Biphasic response after brain death induction: prominent part of catecholamines release in this phenomenon. J Heart Lung Transplant. 2000;19:675-82.

13. Mertes PM, Carteaux JP, Jaboin Y, Pinelli G, el Abassi K, Dopff C, et al. Estimation of myocardial interstitial norepinephrine release after brain death using cardiac microdialysis. Transplantation. 1994;57:371-7.

14. Wittstein IS, Thiemann DR, Lima JA, Baughman KL, Schulman SP, Gerstenblith G, et al. Neurohumoral features of myocardial stunning due to sudden emotional stress. N Engl J Med. 2005;352:539-48.

15. Ghadri JR, Wittstein IS, Prasad A, Sharkey S, Dote K, Akashi YJ, et al. International expert consensus document on Takotsubo syndrome (part I): clinical characteristics, diagnostic criteria, and pathophysiology. Eur Heart J. 2018;39:2032-46.

16. Templin C, Ghadri JR, Diekmann J, Napp LC, Bataiosu DR, Jaguszewski M et al. Clinical features and outcomes of Takotsubo (stress) cardiomyopathy. $N$ Engl J Med. 2015;373:929-38.

17. Shao Y, Redfors B, Scharin Tang M, Mollmann H, Troidl C, Szardien S, et al Novel rat model reveals important roles of beta-adrenoreceptors in stressinduced cardiomyopathy. Int J Cardiol. 2013;168:1943-50.

18. Zaroff JG, Babcock WD, Shiboski SC, Solinger LL, Rosengard BR. Temporal changes in left ventricular systolic function in heart donors: results of serial echocardiography. J Heart Lung Transplant. 2003;22:383-8.

19. Redfors B, Ramunddal T, Oras J, Karason K, Ricksten SE, Dellgren G, et al. Successful heart transplantation from a donor with Takotsubo syndrome. Int J Cardiol. 2015;195:82-4

20. Madan S, Saeed O, Vlismas P, Katsa I, Patel SR, Shin JJ, et al. Outcomes after transplantation of donor hearts with improving left ventricular systolic dysfunction. J Am Coll Cardiol. 2017;70:1248-58.

21. Zaroff JG, Rosengard BR, Armstrong WF, Babcock WD, D'Alessandro A Dec GW, et al. Consensus conference report: maximizing use of organs recovered from the cadaver donor: cardiac recommendations, March 28-29, 2001, Crystal City, Va. Circulation. 2002;106:836-41.

22. Naredi S, Lambert G, Eden E, Zall S, Runnerstam M, Rydenhag B, et al Increased sympathetic nervous activity in patients with nontraumatic subarach noid hemorrhage. Stroke. 2000;31:901-6.

23. Cha KC, Kim HI, Kim OH, Cha YS, Kim H, Lee KH, et al. Echocardiographic patterns of postresuscitation myocardial dysfunction. Resuscitation. 2018;124:90-5.

24. Tryon D, Hasaniya NW, Jabo B, Razzouk AJ, Bailey LL, Rabkin DG. Effect of left ventricular dysfunction on utilization of donor hearts. J Heart Lung Transplant. 2018;37:349-57.

25. Zaroff JG, Rordorf GA, Ogilvy CS, Picard MH. Regional patterns of left ventric ular systolic dysfunction after subarachnoid hemorrhage: evidence for neurally mediated cardiac injury. J Am Soc Echocardiogr. 2000;13:774-9.

26. Oras J, Lundgren J, Redfors B, Brandin D, Omerovic E, Seeman-Lodding H, et al. Takotsubo syndrome in hemodynamically unstable patients admitted to the intensive care unit - a retrospective study. Acta Anaesthesiol Scand. 2017;61:914-24.

27. Chen CW, Sprys MH, Gaffey AC, Chung JJ, Margulies KB, Acker MA, et al Low ejection fraction in donor hearts is not directly associated with increased recipient mortality. J Heart Lung Transplant. 2017;36:611-5.

28. Young JB, Naftel DC, Bourge RC, Kirklin JK, Clemson BS, Porter CB, et al Matching the heart donor and heart transplant recipient. Clues for successful expansion of the donor pool: a multivariable, multiinstitutional report. The Cardiac Transplant Research Database Group. J Heart Lung Transplant. 1994;13: 353-64; discussion: 364-5.

29. Dellgren G, Westerlind A, Liden H, Gabel J, Bartfay SE, Bollano E, et al. Continuous improvement in outcome after heart transplantation-long-term follow-up after three decades of experience. Int J Cardiol. 2017;231:188-94.

Key Words: heart transplantation, heart donation, left ventricular dysfunction, Takotsubo syndrome, heart failure 


\section{APPENDIX E1}

Recommendations for Coronary Angiogram in Potential Heart Donors ${ }^{\text {E1 }}$

1. Male donor aged 35 to 45 years and female donor aged 35 to 50 years: perform angiography if there is a history of cocaine use or $\geq 3$ risk factors for coronary artery disease (CAD), such as hypertension, diabetes, smoking history, dyslipidemia, or family history of premature CAD.

2. Male donor aged 46 to 55 years and female donor aged 51 to 55 years: angiography recommended. However, some of these donors should be considered even if angiography cannot be obtained if the heart is being matched with a higher-risk recipient. The presence of donor risk factors for CAD should be factored into this decision.

3. For age older than 55 years: angiography strongly recommended. An occasional donor can be considered without angiography if being matched with a higher-risk recipient, such as those in urgent need of transplantation because of uncontrollable arrhythmias or hemodynamic deterioration without mechanical support options. The presence of donor risk factors for CAD should be factored into this decision.

\section{Management of the Brain-Dead Organ Donor in the Intensive Care Unit ${ }^{\mathrm{E} 2, \mathrm{E} 3}$}

Monitoring

- Heart rate

- Arterial oxygen saturation $\left(\mathrm{SaO}_{2}\right)$

- Mean arterial pressure $(M A P)$ with an arterial line

- Central venous pressure (CVP)

- Urine output per hour

- Temperature, if possible continuously through esophagus or a urinary catheter

- Nasogastric tube output

- Fluid balance every fourth hour

- Echocardiography when needed according to local routines

- Daily weight

Treatment targets

- Heart rate: 60 to 110 beats per minute

- $\mathrm{SaO}_{2}:>95 \%$

- MAP: 65 to $100 \mathrm{~mm} \mathrm{Hg}$

- CVP: $\leq 10 \mathrm{~mm} \mathrm{Hg}$

- Diuresis: 1 to $2 \mathrm{~mL} / \mathrm{kg} / \mathrm{h}$

- Hemoglobin: $\geq 80 \mathrm{~g} / \mathrm{L}$

- Arterial blood gas analysis: normal pH, partial pressure of oxygen 10 to $13 \mathrm{kPa}$, and partial pressure of carbon dioxide 4.8 to $5.8 \mathrm{kPa}$

- Blood glucose 5 to $10 \mathrm{mmol} / \mathrm{L}$; sodium levels of 135 to $150 \mathrm{mmol} / \mathrm{L}$, potassium and calcium levels within normal range

- Temperature: $35.5^{\circ} \mathrm{C}$ to $38.2^{\circ} \mathrm{C}$
Laboratory samples

- Blood gas analysis, measurement of blood glucose, sodium, and potassium levels initially and at least every fourth hour

- Measurement of complete blood count, serum levels of creatinine, aspartate transaminase, alanine transaminase, alkaline phosphatase, bilirubin, gamma-glutamyltransferase, lactate dehydrogenase, amylase, albumin, prothrombine time, activated partial thromboplastin time, and C-reactive protein initially and thereafter once a day

- Blood grouping and crossmatching

Treatment recommendations

Circulation

- Hypovolemia

Treated with crystalloid fluid and/or colloids (albu$\mathrm{min}$ ) to a maximum CVP of $10 \mathrm{~mm} \mathrm{Hg}$. Avoid fluid overload. Higher CVP values increase the risk of edema in the liver and lungs with impaired organ function as a consequence. Crystalloids are used restrictively for potential lung donors because of the risk of lung edema for the donor, and to limit the reperfusion edema in the lung recipient. Consider blood components if needed

- Hypotension (MAP $<65 \mathrm{~mm} \mathrm{Hg}$ )

Low systemic vascular resistance is treated with targeted infusion of vasopressor drugs. Norepinephrine is the first drug of choice. Alternatively, vasopressin is given, depending on local routines. If decreased cardiac performance with the need of inotropic support, dobutamine is the first drug of choice

- Hypertension (MAP >100 mm Hg)

Treated with labetalol. After brain death nitroglycerin can be used. If hypertension with simultaneous tachycardia, labetalol and $\beta$-blockers are used intravenously

- Tachycardia ( $>110$ beats per minute)

If the donor still shows tachycardia despite optimized ventilation, circulation, and temperature, treatment with $\beta$-blockers is indicated if no cardiac failure is present

- Bradycardia ( $<50$ beats per minute)

Treated with targeted infusion of isoprenaline. Cholinergic antagonists have no effect in the donor because of the loss of function of the vagus nerve

Respiration

- Normoventilation

1341.e1 The Journal of Thoracic and Cardiovascular Surgery • April 2020 
Aim at partial pressure of oxygen 10 to $13 \mathrm{kPa}$, arterial oxygen saturation $>95 \%$, and partial pressure of carbon dioxide 4.8 to $5.8 \mathrm{kPa}$

- Lung protective ventilation Plateau pressure $<30 \mathrm{cmH}_{2} \mathrm{O}$. PEEP 5-15 $\mathrm{cmH}_{2} \mathrm{O}$. Tidal volume 6 to $8 \mathrm{~mL} / \mathrm{kg}$ on the basis of the donor's ideal body weight

- Avoid atelectasis

Keep the lung open with recruitment maneuvers according to local routines

- Keep the lung dry

Crystalloids are used restrictively to potential lung donors because of the risk of lung edema for the donor, and to limit the reperfusion edema in the lung recipient

Hormonal changes

- Treatment with desmopressin is initiated immediately after diabetes insipidus has been diagnosed Desmopressin injection 0.25 to $0.5 \mu \mathrm{g}$ intravenously or desmopressin acetate $0.75 \mu \mathrm{g} / \mathrm{mL}$, 0.25 to $0.5 \mathrm{~mL}$ intravenously or infusion of vasopressin $\leq 2.5 \mathrm{E} / \mathrm{h}$, which is suitable if the donor also is hypotensive

- After brain death has been confirmed, methylprednisolone $15 \mathrm{mg} / \mathrm{kg}$, as a bolus, is administered

- No thyroid hormones are administered (according to local guidelines, not stipulated in general guidelines)

Metabolism

- Hyperglycemia is common in the donor because of increased resistance to insulin and can impair the transplanted organ function. Aim at B-glucose of $5.10 \mathrm{mmol} / \mathrm{L}$ with continuous infusion of insulin and glucose according to local routines

\section{E-References}

E1. Zaroff JG, Rosengard BR, Armstrong WF, Babcock WD, D'Alessandro A, Dec GW, et al. Consensus conference report: maximizing use of organs recovered from the cadaver donor: cardiac recommendations, March 28-29, 2001, Crystal City, Va. Circulation. 2002;106:836-41.

E2. McKeown DW. Management of the heartbeating brain-dead organ donor. $\mathrm{Br} J$ Anaesth. 2012;108(Suppl 1):i96-107.

E3. European Committee on Organ Transplantation. Guide to the Quality and Safety of Organs for Transplantation. 5th ed. Strasbourg, France: Council of Europe 2013. 
Circumferential pattern

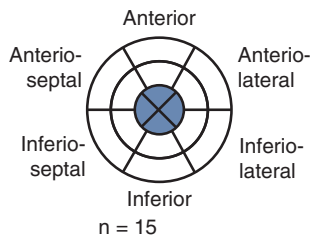

Focal wall motion pattern
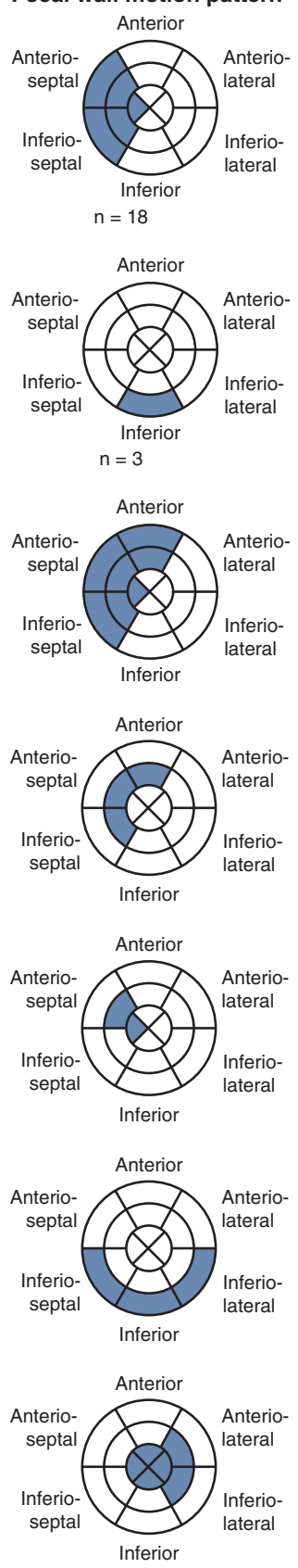
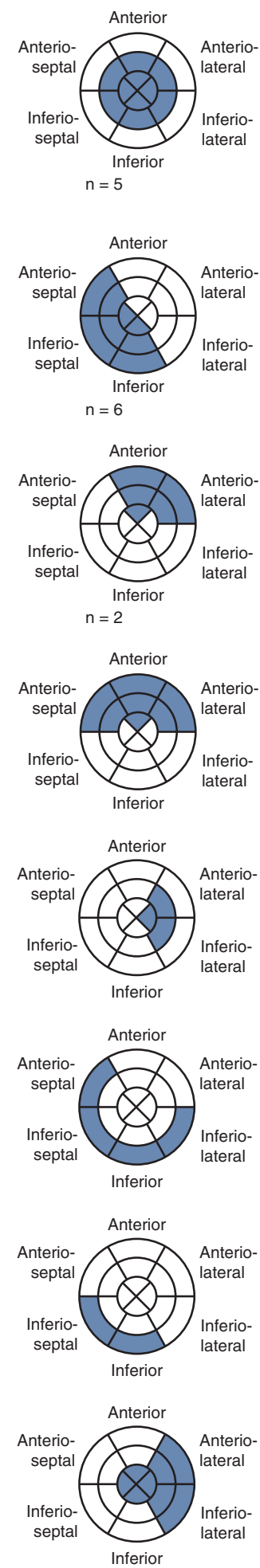
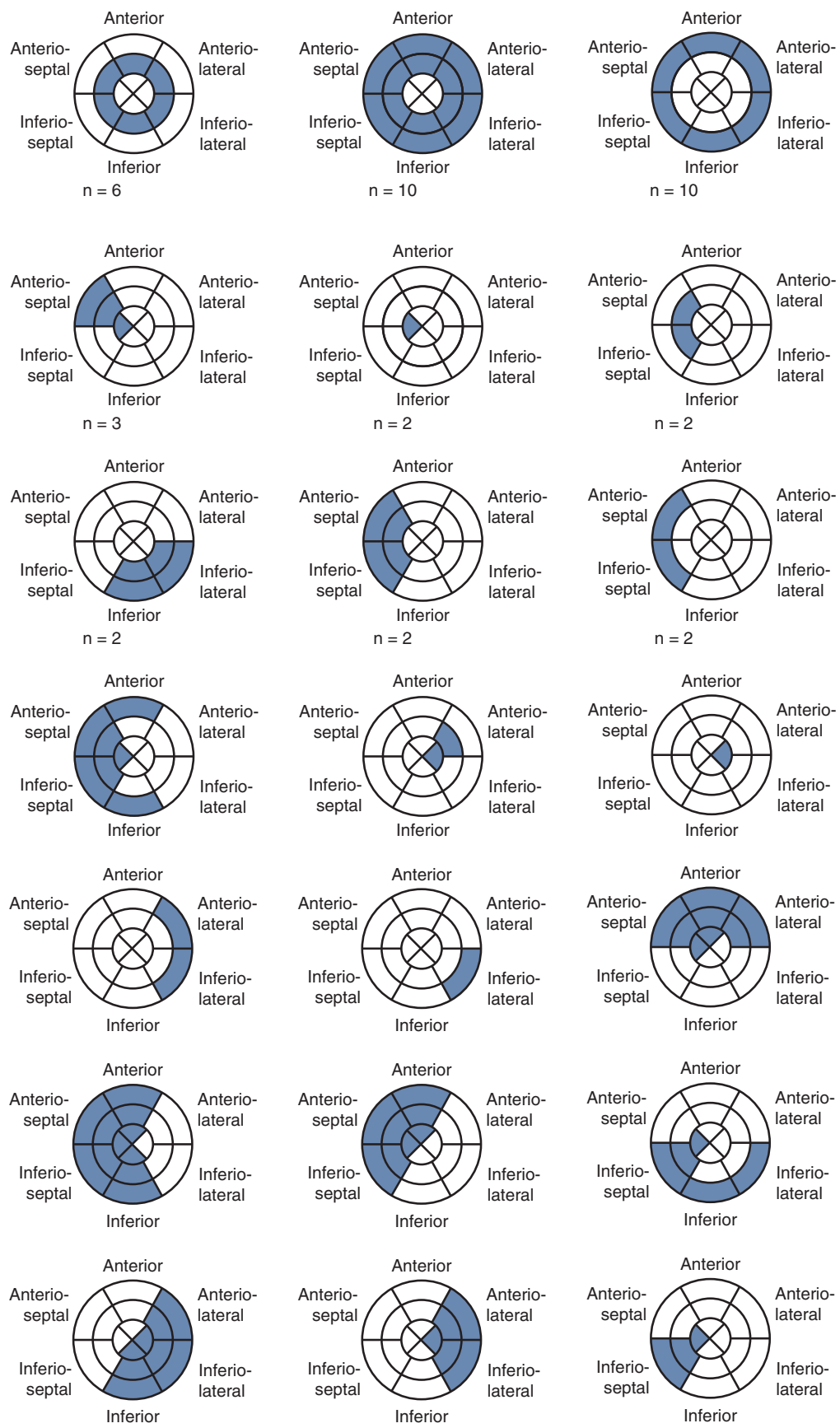

FIGURE E1. Distribution of hypokinesia in potential heart donors with regional wall motion abnormalities. Blue areas represent segments with regional wall motion abnormalities. 


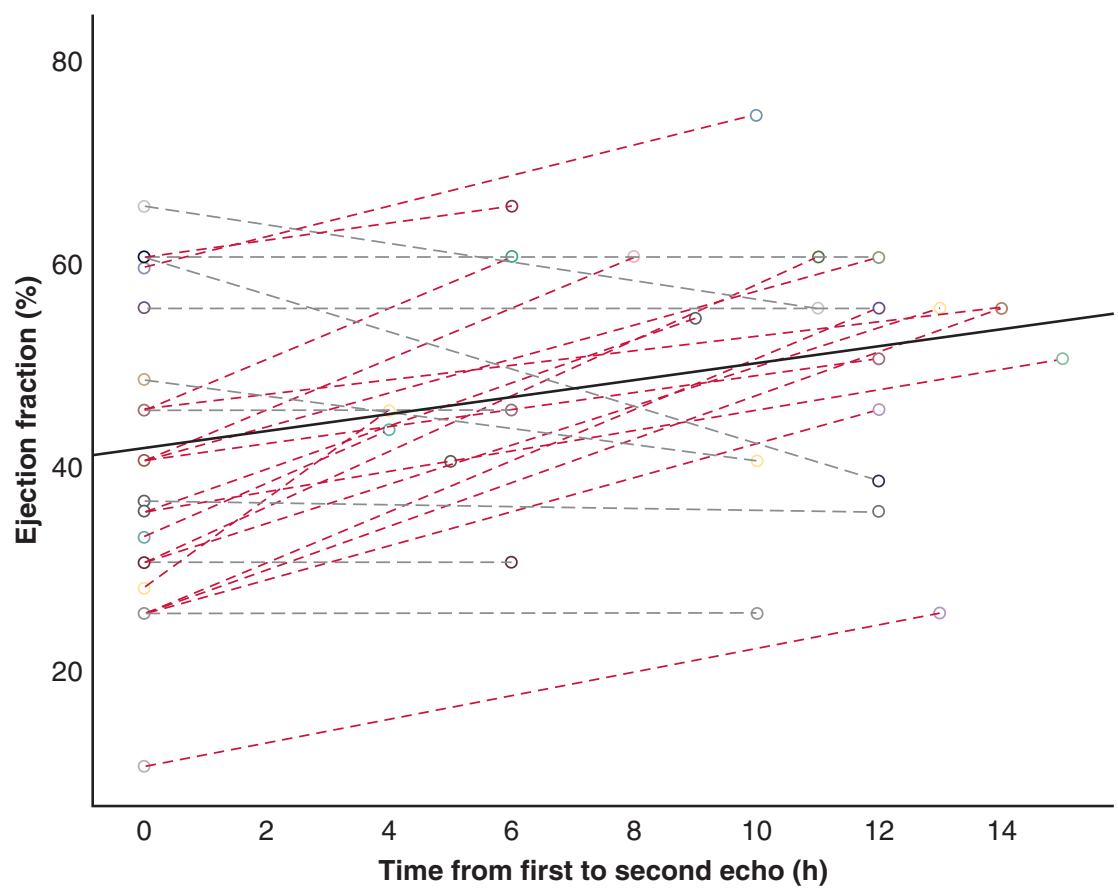

FIGURE E2. Temporal changes in ejection fraction (EF) for each single donor during the 24-hour donation process. In 7 donors, the precise timing of the repeated echocardiography (echo) was not available and was extrapolated to 12 hours. The red dashed lines indicate donors with improvement of left ventricular function. Two donors had normal EF at the first echo with normalization of regional wall motion abnormalities and improvement in EF. Gray dashed lines represent donors with no change or deterioration of EF. The solid black line represents the mean temporal change in EF.

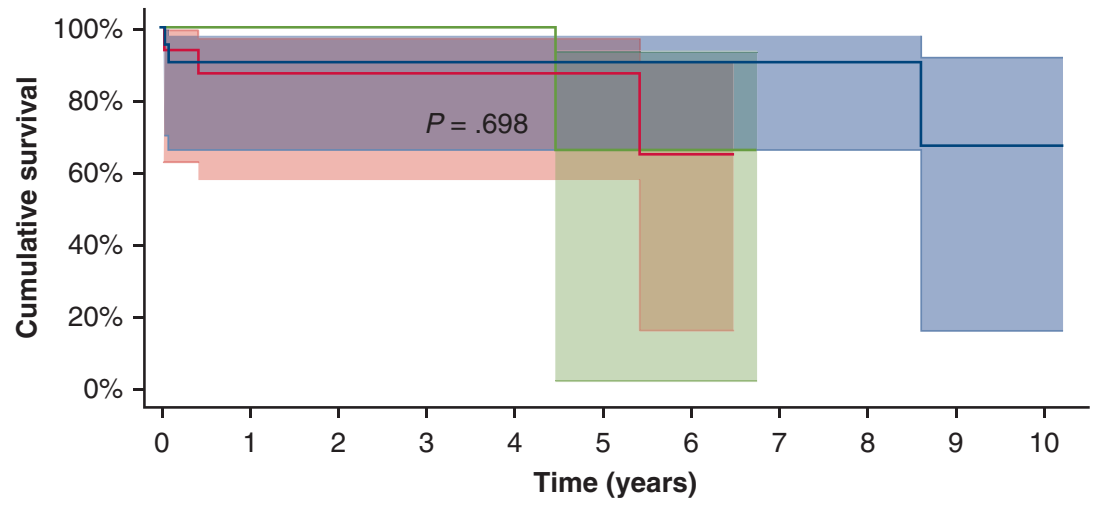

\begin{tabular}{|c|c|c|c|c|c|c|}
\hline \multicolumn{7}{|l|}{ Numbers at risk } \\
\hline Preseved EF 21 & 16 & 14 & 10 & 9 & 9 & 6 \\
\hline EF $40-49 \% 16$ & 14 & 11 & 9 & 7 & 4 & 1 \\
\hline$E F<40 \% 5$ & 5 & 5 & 3 & 3 & 2 & 2 \\
\hline & & & $\begin{array}{r}\text { ecipie } \\
-\mathrm{P} \\
-\mathrm{E}\end{array}$ & $\begin{array}{l}\text { ИA } \\
0-\end{array}$ & $\partial r n$ & $\begin{array}{l}\text { ts with: } \\
\text { rved EF }\end{array}$ \\
\hline
\end{tabular}

FIGURE E3. Long-term outcomes of the recipients of hearts with regional hypokinesia and preserved ejection fraction (EF; blue line), EF $40 \%$ to $49 \%$ (red line), and $\mathrm{EF}<40 \%$ (green line). The events represented include death and retransplantation. There were no differences in events over time between the groups. Shaded areas represent $95 \%$ confidence interval. RWMA, Regional wall motion abnormalities. 


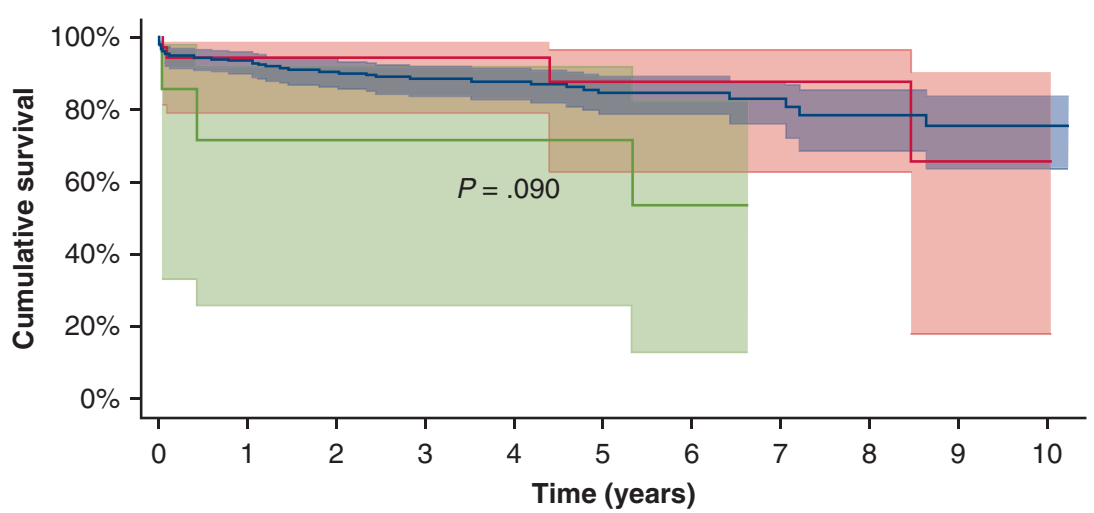

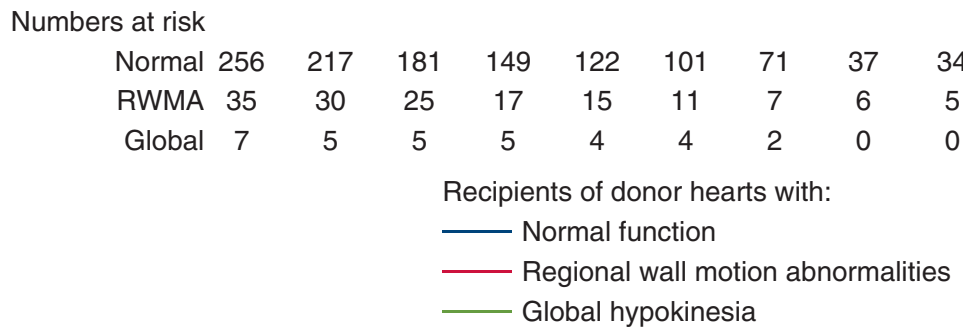

FIGURE E4. Long-term outcomes of the recipients of hearts with normal function (blue line), regional wall motion abnormalities (RWMA; red line), and global hypokinesia (green line). The events represented include death and retransplantation. There were no differences in events over time between the groups. Shaded areas represent $95 \%$ confidence interval.

TABLE E1. Characteristics of used donors with normal function and left ventricular dysfunction

\begin{tabular}{|c|c|c|c|c|}
\hline \multirow[b]{2}{*}{ Category } & \multirow[b]{2}{*}{ Variable } & \multicolumn{2}{|c|}{ Donor heart } & \multirow[b]{2}{*}{$P$ value } \\
\hline & & Normal function $(n=293)$ & $\begin{array}{l}\text { Left ventricular dysfunction } \\
\qquad(n=45)\end{array}$ & \\
\hline \multirow[t]{3}{*}{ Background data } & Age, y & $49(32-57)$ & $46(24-54)$ & .396 \\
\hline & Female sex, n $(\%)$ & 139 (47) & $22(49)$ & .872 \\
\hline & BMI & $24 \pm 5$ & $25 \pm 5$ & .188 \\
\hline Medical history & Risk factor of CAD, n (\%) & $142(48)$ & $23(51)$ & .747 \\
\hline \multirow[t]{4}{*}{ Cause of death } & Hypoxic brain edema, n (\%) & $58(20)$ & $13(29)$ & .166 \\
\hline & Cerebral insult, $\mathrm{n}(\%)$ & $168(57)$ & $22(49)$ & .415 \\
\hline & Traumatic brain injury, $\mathrm{n}(\%)$ & $60(20)$ & $9(20)$ & $>.999$ \\
\hline & Other, $\mathrm{n}(\%)$ & $7(2)$ & $1(2)$ & $>.999$ \\
\hline Contributing factors & Cardiac arrest, $\mathrm{n}(\%)$ & $81(28)$ & $16(36)$ & .285 \\
\hline
\end{tabular}

$B M I$, Body mass index; $C A D$, coronary artery disease. 
TABLE E2. Pretransplantation characteristics of recipients of hearts with normal function and left ventricular dysfunction for patients at Gothenburg Transplantation Centre

\begin{tabular}{|c|c|c|c|c|}
\hline \multirow[b]{2}{*}{ Category } & \multirow[b]{2}{*}{ Variable } & \multicolumn{2}{|c|}{ Recipient of donor heart with } & \multirow[b]{2}{*}{$P$ value } \\
\hline & & Normal function $(n=238)$ & Left ventricular dysfunction $(n=38)$ & \\
\hline \multirow[t]{7}{*}{ Background data } & Age, $y$ & $49(27-61)$ & $42(28-59)$ & .888 \\
\hline & Sex, n (\%) & $67(28)$ & $10(26)$ & $>.999$ \\
\hline & BMI & $26 \pm 4$ & $26 \pm 5$ & .719 \\
\hline & NYHA class (range) & $1(1-1)$ & $1(1-2)$ & .205 \\
\hline & Ejection fraction (range), $\%$ & $20(19-30)$ & $20(15-30)$ & .204 \\
\hline & VAD/ECMO, n (\%) & $64(27)$ & $14(37)$ & .162 \\
\hline & PVR, Wood units & $2.3(1.5-3.4)$ & $2.5(1.5-3.3)$ & .990 \\
\hline \multirow[t]{9}{*}{ Medical history } & Active smoker, $\mathrm{n}(\%)$ & $18(8)$ & $0(0)$ & .136 \\
\hline & History of smoking, $\mathrm{n}(\%)$ & $62(26)$ & $10(26)$ & $>.999$ \\
\hline & Hypertension, $\mathrm{n}(\%)$ & $23(10)$ & $2(5)$ & .549 \\
\hline & Diabetes, n (\%) & $28(12)$ & $2(5)$ & .392 \\
\hline & Cerebrovascular disease, $\mathrm{n}(\%)$ & $28(12)$ & $6(16)$ & .415 \\
\hline & COPD, n (\%) & $6(3)$ & $1(3)$ & $>.999$ \\
\hline & Osteoporosis, $\mathrm{n}(\%)$ & $5(2)$ & $0(0)$ & $>.999$ \\
\hline & Pulmonary embolism, n (\%) & $3(1)$ & $1(3)$ & .432 \\
\hline & Systematic inflammatory disease, $\mathrm{n}(\%)$ & $27(11)$ & $5(13)$ & .590 \\
\hline \multirow[t]{2}{*}{ Perioperative data } & ECC time (range), minutes & $165(139-202)$ & $167(141-216)$ & .686 \\
\hline & Ischemia time (range), minutes & $205(162-237)$ & $203(162-231)$ & .686 \\
\hline
\end{tabular}

BMI, Body mass index; NYHA, New York Heart Association classification of heart failure; VAD, ventricular assist device; $E C M O$, extracorporeal membrane oxygenation; $P V R$, pulmonary vascular resistance; $C O P D$, chronic obstructive pulmonary disease; $E C C$, extracorporeal circulation. 